\title{
A CLINICAL FACTOR ANALYTIC METHOD FOR INFERRING CONSTRUCT MEANING
}

\author{
MARII.YN S. KOLTON AND LOUIS DWARSHUIS \\ Center for Research on Utilization of Scientific Knowledge \\ Institute for Social Research \\ University of Michigan, Ann Arbor
}

THE Changing Jobs project of the Industry and Health program at the Institute for Social Research makes use of many scales to assess changes in attitude, motivation, drive, and other aspects of personality affected by the loss and the subsequent obtaining of a job among long-term employees affected by the closing of a plant. The Changing Jobs project made use of three major personality questionnaires. These were the: CrowneMarlowe, the Ego Resilience Scale of the MMPI, and the Flexibility-Rigidity Scale of the California Psychological Inventory. These scales were used because they assess postulated attributes of individuals assumed to be very much affected by the change in self-esteem and vulnerability to threat that precedes and continues during unemployment and job seeking. These characteristics also show changes for the positive when a person finds a new job. These constructs have all been supported to a greater or lesser degree by empirical tests. These psychological tests have been proven valid for situations they were originally designed to measure. Methods used for replicating and determining subgroups of items and the total scale are usually restircted to a certain kind of group under a particular situation."When these same constructs are used for testing a series of hypotheses generated in a new situation one can no longer be sure that the instruments are construct valid for this new situation. If an expected trend does not emerge in data analysis, both the inter- 
pretation of the construct and the experimental methodology can be questioned. If an expected trend does emerge, the possibility of opposite trends and constructs fortuitiously producing expected results cannot be ruled out.

If the three tests are measuring separate and distinguishable personality constructs, we would expect a low correlation between the three tests. Although the occurrence of a low correlation between tests would not insure construct clarity, a lack of construct clarity is suggested by the high intertest correlations of Need for Social Approval, Flexibility-Rigidity, and Ego Resilience. Both Flexibility-Rigidity and Ego Resilience correlate at approximately .40 with the Need for Social Approval. Flexibility-Rigidity and Ego Resilience correlate at less than .20. Subscale analyses of these personality questionnaires are limited by the experimenter's interest and by the purpose and population of the studies. Interrelating the various subfactors from different instruments is very difficult because of the unknown effects related to the particular uses of the questionnaires. An empirical approach to construct definition cannot overcome either the unknown dissimilarities in purpose and in population of test administration or the lack of multi-groups and multi-method approaches. Another approach open to the investigator is to design questions to fit a construct. What seems to have face validity for the author, however, does not necessarily have construct validity.

In an attempt to reach greater conceptual clarity, the authors used another alternative which we named the clinical factor analytic approach. This method combines a clinical experience and judgment with the analytic power of an empirical approach. The clinicians first determine the possible constructs that are reflected in the total item pool. These constructs should be fairly inclusive, should allow a single question to be scored on many constructs, and should permit a range of possible interpretations for an item. All items are then scored positive, negative, or not applicable for each construct by the two clinicians. This scoring process should continue to develop until there is a sufficiently high interrater reliability. Constructs with similar ratings across items are then either eliminated or condensed. All items within one of the remaining constructs are then given a forced choice 
scoring on only one of the remaining dimensions by the two clinicians. Items remaining with a forced choice rating within the same content dimension are then treated as belonging to this dimension. If clinical rater reliability for a dimension is poor, that dimension is eliminated at this point. All items are then put in the form of an intercorrelational matrix and factor analyzed. Factors that account for at least five per cent of the variance are then related to the final clinical judgments of item meaning. The resulting agreement allows for easy naming of the factors and an excellent grasp of their meaning in a particular situation. After first reading all the questions in the data pool, we devised on the basis of clinical experience as many overriding constructs as necessary to cover whatever might conceivably be common to all three of the personality questionnaires. The constructs used are presented in Table 1 .

All items were put in a common item pool and scored by two clinical psychologists on applicable dimensions. Some items appeared on the basis of clinical judgment to reflect as many as eight of these constructs.

A comparison was made of the consistency of response direction for each of the ten dimensions for each personality questionnaire. The question we were interested in was whether the items in a test such as the Crowne-Marlowe align themselves in a single direction according to the accepted scoring of the test or whether some items group around various constructs. If a test such as the Crowne-Marlowe did not unidirectionally measure a construct, it was assumed that the test authors did not

TABLE 1

Clinically Inferred Constructs in the Crowne-Marlowe, California Personality Inventory, and MMPI Ego-Resilience Scale

Impulse Expression

Self-Acceptance

Social Inhibition

Introversion

Submission

Insecurity

Passivity

Anxiety

Trust-Distrust

Intellectual Curiosity 
intend to measure this subconstruct and may have lacked clarity in defining their construct.

The three personality questionnaires were then compared for the points of agreement on the 10 clinically judged construct dimension. Both the Crowne-Marlowe and the California Personality Inventory appeared to be assessing Impulse Expression, but the Ego Resilience Scale did not measure this construct. The California Personality Inventory and the Ego Resilience Scale, but not the Crowne-Marlowe, appeared to be assessing Self Acceptance. All three tests seemed to measure InsecurityAnxiety and Distrust. The constructs Introversion and Passivity did not align themselves in a single direction according to the accepted scoring of the total item pool. Additionally the smallest number of items described these two constructs. A comparison of the 10 constructs revealed that Introversion was described by a subset of the same items used to describe Social Inhibition; Passivity was described by a subset of items used to describe Insecurity.

Among the remaining constructs, Submission seemed the most difficult to score. Most of the disagreements between the two clinical judges occurred on this construct. The scoring profiles for the constructs Submission and Passivity were very similar and both profiles were similar to the profiles for the constructs Anxiety and Insecurity. It appeared that little discrimination was achieved by retaining the separate constructs and a summary construct Insecurity-Anxiety seemed to represent well the separate constructs.

At this point in the evaluation process, six summary constructs inclusive of the 10 original constructs remained. These constructs and the subconstructs included in them are presented in Table 2. There was a great deal of overlap between items of different constructs. Some items seemed to represent several constructs. An attempt was then made to select the most representative items within a construct. Items in a pool for a particular construct were force-choiced into one construct subset and eliminated from all others. Intercorrelations were then computed for all items for the remaining constructs. Separate matrices were then pulled from the large matrix for each construct in order to see if the construct as defined by the items was internally consistent. 
TABLE 2

Summary Constructs for the Three Personality Tests

Impulse Expression
Self-Acceptance
Social Inbibition
Introversion
Insecurity-Anxiety
Passivity
Submission
Trust-Distrust
Intellectual Curiosity

The presence of high intercorrelations within the resulting matrix was used as a criteria for internal consistency.

The constructs Trust-Distrust and Insecurity-Anxiety did not have sufficiently high internal consistency. When items from these constructs were internally consistent with items from another construct they were used in that construct's matrix. Items with low intercorrelations (average interitem correlation less than .2) were eliminated from the construct matrices. The total number of items in the remaining four constructs were reduced to 70 . These items were then put in a new correlation matrix and were factor analyzed. The four factors which emerged and the variances they account for are presented in Table 3.

The first four factors accounted for 55 per cent of the variance. Each of the remaining factors accounted for less than six per cent of the variance and were not interpreted. The four factors were interpreted as essentially the same four factors used as input into the factor analysis.

The first factor, Openness-Flexibility, accounted for 27 per cent of the variance. It is made up entirely of items from the California Psychological Inventory. The items in this factor

TABLE 3

Four Factors and Their Variances

\begin{tabular}{rlc}
\hline \multicolumn{1}{c}{ Factor } & Variance \\
\hline I. & Openess-Flexibility & $27 \%$ \\
II. Acceptance of Impulse Expression & $10 \%$ \\
III. Self-Acceptance & $7 \%$ \\
IV. Social Inhibition & $6 \%$ \\
\hline
\end{tabular}


are presented in Table 4 . These items were well represented in the original clinical construct "Openness to New Ideas." The factor includes most of the items from the construct Intellectual Curiosity. Ten of a total of 19 items in the original clinical sort of the total item pool are in the final Factor $I$ of the factor analysis. The first factor is made up primarily of items comprising the Katz Factors I and III including six of the seven items in these scales. Only three of the items from Factors II and IV are included in Factor $\mathrm{I}$ of the present factor analysis. This suggests that Factor I may be more fully tapping the construct "Openness-Flexibility" and less so that part of the original California Psychological Inventory construct involving "ActivityPassivity."

The second factor, Acceptance of Impulse Expression, accounted

TABLE 4

Test Items and Their Factor Loadings for Factor I, Flexibility-Openness

\begin{tabular}{|c|c|c|}
\hline Test & Items & $\begin{array}{l}\text { Factor } \\
\text { Loadings }\end{array}$ \\
\hline CPI & Once I have my mind made up I seldom change it & .61 \\
\hline CPI & $\begin{array}{l}\text { For most questions, there is just one right answer, once a } \\
\text { person is able to get all the facts }\end{array}$ & .59 \\
\hline CPI & $\begin{array}{l}\text { People who seem unsure and uncertain about things make } \\
\text { me feel uncomfortable }\end{array}$ & .57 \\
\hline CPI & $\begin{array}{l}\text { Our thinking would be a lot better off if we would just forget } \\
\text { about words like "probably," "approximately," and } \\
\text { "perhaps" }\end{array}$ & .56 \\
\hline CPI & $\begin{array}{l}\text { It is hard for me to sympathize with someone who is always } \\
\text { doubting and unsure about things }\end{array}$ & .56 \\
\hline CPI & $\begin{array}{l}\text { I set a high standard for myself and feel others should do } \\
\text { the same }\end{array}$ & .53 \\
\hline CPI & $\begin{array}{l}\text { A strong person will be able to make up his mind even on } \\
\text { the most difficult questions }\end{array}$ & .52 \\
\hline CPI & $\begin{array}{l}\text { I like to have a place for everything and everything in its } \\
\text { place }\end{array}$ & .51 \\
\hline CPI & $\begin{array}{l}\text { The trouble with many people is that they don't take things } \\
\text { seriously enough }\end{array}$ & .48 \\
\hline CPI & $\begin{array}{l}\text { I don't like to work on a problem unless there is a possi- } \\
\text { bility of coming out with a clear-cut answer }\end{array}$ & .47 \\
\hline CPI & $\begin{array}{l}\text { It bothers me when something unexpected interrupts my } \\
\text { daily routine }\end{array}$ & .45 \\
\hline CPI & $\begin{array}{l}\text { I always see that my work is carefully planned and } \\
\text { organized }\end{array}$ & .44 \\
\hline CPI & $\begin{array}{l}\text { I am in favor of a very strict enforcement of all laws, no } \\
\text { matter what the consequences }\end{array}$ & .44 \\
\hline CPI & I don't like things to be uncertain and unpredictable & .44 \\
\hline CPI & I am known as a hard and steady worker & .44 \\
\hline
\end{tabular}


for 10 per cent of the variance. It is made up primarily of Crowne-Marlowe items. These items are presented in Table 5 . The items were well represented in the original clinical constructs Impulse Expression, Introversion, and Feelings of Insecurity. The second factor is made up primarily of items concerned with denying aggression and bad behavior.

The third factor, Self-Acceptance, accounted for seven per cent of the variance. The items in this factor are presented in Table 6 . The factor has Crowne-Marlowe items from subscales negatively loading in relation to subscale 2 and items marked true on the Ego Resilience Scale. The items in this factor were well represented in the original clinical construct "Self-Acceptance" and "Trust."

The fourth factor, Social Inhibition, accounted for 6 per cent of the variance. The test items for this factor are presented in Table 7. It has its highest loadings on items from subscale 3 of the Crowne-Marlowe. Additional high loadings occur on re-

TABLE 5

Test Items and Their Factor Loadings for Factor II, Acceptance of Impulse Expression

\begin{tabular}{|c|c|c|}
\hline Test & Items & $\begin{array}{l}\text { Factor } \\
\text { Loadings }\end{array}$ \\
\hline $\mathbf{C}-\mathbf{M}$ & I sometimes feel resentful when I do not get my way & .60 \\
\hline C-M & $\begin{array}{l}\text { On occasion I have had doubts about my ability to succeed } \\
\text { in life }\end{array}$ & .56 \\
\hline C-M & $\begin{array}{l}\text { At times I have really insisted on having things my own } \\
\text { way }\end{array}$ & .55 \\
\hline $\mathrm{C}-\mathrm{M}$ & $\begin{array}{l}\text { There have been times when I was quite jealous of the } \\
\text { good fortune of others }\end{array}$ & .52 \\
\hline C-M & $\begin{array}{l}\text { On a few occasions, I have given up doing something be- } \\
\text { cause I thought too little of my ability }\end{array}$ & .51 \\
\hline MMPI & I wish I were not so shy & .49 \\
\hline $\mathrm{C}-\mathrm{M}$ & I am sometimes irritated by people who ask favors of me & .49 \\
\hline $\mathrm{C}-\mathrm{M}$ & $\begin{array}{l}\text { It is sometimes hard for me to go on with my work if I am } \\
\text { not encouraged }\end{array}$ & .43 \\
\hline $\mathrm{C}-\mathrm{M}$ & There have been occasions when I felt like smashing things & .42 \\
\hline $\mathrm{C}-\mathrm{M}$ & $\begin{array}{l}\text { I sometimes think when people have a misfortune they only } \\
\text { got what they deserved }\end{array}$ & .40 \\
\hline C-M & I am always willing to admit it when I make a mistake & -.37 \\
\hline MMPI & I of ten must sleep over a matter before I decide what to do & .36 \\
\hline MMPI & $\begin{array}{l}\text { I frequently find it necessary to stand up for what I think is } \\
\text { right }\end{array}$ & .34 \\
\hline C-M & No matter who I am talking to, I am always a good listener & -.33 \\
\hline MMPI & I am easily awakened by noise & .30 \\
\hline
\end{tabular}


TABLE 6

Test Items and Their Factor Loadings for Factor III, Self-Acceptance

\begin{tabular}{|c|c|c|}
\hline Test & Items & $\begin{array}{c}\text { Factor } \\
\text { Loadings }\end{array}$ \\
\hline C-M & $\begin{array}{l}\text { When I don't know something I do not at all mind ad- } \\
\text { mitting it. }\end{array}$ & -.69 \\
\hline MMPI & Religion gives me no worry & -.47 \\
\hline $\mathrm{C}-\mathrm{M}$ & I sometimes try to get even rather than forgive and forget & .46 \\
\hline $\mathrm{C}-\mathrm{M}$ & I always try to practice what I preach & -.46 \\
\hline MMPI & I practically never blush & -.44 \\
\hline MMPI & I daydream very little & -.42 \\
\hline $\mathrm{C}-\mathrm{M}$ & I am always courteous, even to people who are disagreeable & -.34 \\
\hline C-M & $\begin{array}{l}\text { There have been times when I felt like rebelling against } \\
\text { people in authority even though I knew they were right }\end{array}$ & .32 \\
\hline C-M & I never resent being asked to return a favor & -.28 \\
\hline MMPI & I do not mind being made fun of & -.26 \\
\hline MMPI & I almost never dream & -.25 \\
\hline
\end{tabular}

sponses marked false on the Ego Resilience Scale and on one item of subscale 4 of the Crowne-Marlowe. The fourth factor items were well represented in the original clinical constructs "Social Inhibition" and "Distrust."

Further analysis of factors was not attempted because the variance accounted for by the remaining factors fell below five per cent.

Comparing the four factors from the factor analysis with the

TABLE 7

Test Items and Their Factor Loadings for Factor IV, Social Inhibition

\begin{tabular}{|c|c|c|}
\hline Test & Items & $\begin{array}{l}\text { Factor } \\
\text { Loadings }\end{array}$ \\
\hline $\mathrm{C}-\mathrm{M}$ & I am always careful about my manner of dress & -.71 \\
\hline $\mathrm{C}-\mathrm{M}$ & $\begin{array}{l}\text { Before voting I thoroughly investigate the qualifications of } \\
\text { all the candidates }\end{array}$ & -.42 \\
\hline MMPI & $\begin{array}{l}\text { I have of ten felt badly over being misunderstood when } \\
\text { trying to keep someone from making a mistake }\end{array}$ & -.38 \\
\hline C-M & $\begin{array}{l}\text { I never make a long trip without checking the safety of my } \\
\text { car }\end{array}$ & -.37 \\
\hline C-M & $\begin{array}{l}\text { I never hesitate to go out of may way to help someone in } \\
\text { trouble }\end{array}$ & -.37 \\
\hline MMPI & $\begin{array}{l}\text { It takes a lot of argument to convince most people of the } \\
\text { truth }\end{array}$ & -.31 \\
\hline CPI & I like a well-ordered life with regular hours & -.31 \\
\hline $\mathrm{C}-\mathrm{M}$ & $\begin{array}{l}\text { I have never been irked when people expressed ideas very } \\
\text { different from my own }\end{array}$ & -.31 \\
\hline C-M & I like to gossip at times & .25 \\
\hline $\mathrm{C}-\mathrm{M}$ & $\begin{array}{l}\text { There have been occasions when I took advantage of some- } \\
\text { one }\end{array}$ & .23 \\
\hline
\end{tabular}


original scales and the clinical judgment of content meaning, suggest that the California Psychological Inventory may be a two factor scale tapping not only "Openness-Flexibility" but also "Activity-Passivity." Factor I appears to be tapping Openness-Flexibility but does not include Activity-Passivity.

The Crowne-Marlowe scale seems to factor along denial and approval dimensions. Factor 2 appears to heavily load on items representing the denial of unacceptable impulses; Factor 3 heavily loads on items representing positive self-image or self-acceptance; Factor 4 appears to heavily load on items representing denial of social inhibitions.

The Ego Resilience Scale does not appear to have a well defined subfactor structure. It loads on three of the four factors according to the similarity of item content with other scale items.

The strong directional loading of the factors might at first thought suggest a response bias explanation of factor structure. However, the original scoring of the California Psychological Inventory and Crowne-Marlowe may well account for any apparent response bias. The original direction of scoring is along a true or false dimension and the appearance of factors along a true or false dimension does little more than prove the validity of the original scoring of the items by the test maker. It does not invalidate interpretations of the factors that ignore response bias.

A combined clinical factor analytic approach to analyzing items coming from a variety of scales and subscales offers the advantage of allowing new factor structures to emerge, while using previous subfactor knowledge in interpreting these new factors. The initial clinical judgment task can often add to the interpretability of the final factors. The approach looks at individual integration of variables as they function in personality viewed from a person oriented framework, using clinical intuition. This clinical factor analytic method for inferring construct meaning when combined with a statistical analysis can add considerably to the probability of valid interpretation. 